\title{
Development of Visual Mathematics Literacy Scale for Elementary Education Mathematics Teacher Candidates ${ }^{*}$
}

\author{
Aziz ILHAN \\ Tunceli University, Tunceli, Turkey \\ H. Coşkun ÇELIKK \\ Siirt University, Siirt, Turkey
}

\begin{abstract}
The purpose of this study is to develop a valid, reliable, and useful scale for measuring visual mathematics literacy of teacher candidates. To that end, an item pool consisting of 60 items of pentad Likert type is established by making use of resources related to subject and opinions of teacher candidates. In accordance with expert opinions, four of the 60 items were removed from the scale and a 54 items scale form draft was prepared. Draft scale has been applied to 325 students studying in the mathematics teacher programs of Faculty of Education, Cumhuriyet University and Faculty of Education, Dicle University Ziya Gökalp in the first semester of 2014-2015 academic years. As a result of data analysis, a visual mathematics literacy scale (VMLS) in pentad Likert type with 37 items is developed. It is observed that 37 items in the final scale are gathered under five factors and total variance ratio explained by these factors is $44.246 \%$. Cronbach alpha internal consistency coefficient of the scale is calculated as 0.904 . In the end of the study, a valid and reliable scale to determine the visual mathematics literacy of teacher candidates has been developed.

Keywords: mathematics teacher candidates, visual mathematics literacy, mathematics literacy, mathematics education, scale development
\end{abstract}

\section{Introduction}

As there will be no science without mathematics and no technology without science, similarly, an individual who have not gained basic mathematics knowledge and skills will have various problems in living his/her life and throughout his/her learning process. Learning of mathematics and being aware of mathematical ideas by children and young people can only be ensured by verbal, numerical, visual, symbolic, and written communication in Mathematics. Hence, "mathematics for everyone," "mathematics literacy," and "grow stronger in mathematics" are beyond being catch-phrases and became a main purpose to reach in education and a field of training and research where every community must invest in (Ersoy, 2003).

\section{Literature Review}

Literacy is described as "individuals ability to maintain his/her life in the community he/she lives in,

\footnotetext{
${ }^{*}$ This study was presented in International Education Congress (ICEFIC) as verbal statement.

Aziz İLHAN, instructor, Accounting Department Head, Department of Computer Technology, Çemişgezek Vocational High School, Tunceli University.

H. Coşkun ÇELIK, Dr., assistant professor, Primary Education Department, Primary Education Mathematics Teaching Program, Faculty of Education, Siirt University.
} 
ability to read-write to communicate with the community, and ability to manage basic mathematical operations" by Karunaratne (2000) (as cited in Duran, 2012). As it can be seen that the concept of mathematics is even in the core of literacy term. Visual literacy concept first emerged by the end of 1960's. First definition was made by Debes (1968), "Visual literacy is a name given to a series of sight competence developed by humans by using eyesight. Development of these competencies forms a basis for learning. A person with these competences has developed the skill of distinguishing and interpreting the visual movements, objects, symbols, and other things around him/her. By using these competencies creatively, humans communicate with others and use visual communication better." Later, visual literacy was defined by Hortin (1980) as "Visual literacy is the capacity of reading and understanding visual elements and skill of thinking and learning by visual elements, i.e., thinking visually" (as cited in Sanalan, Sülün, \& Çoban, 2007). In the 20th century, especially in the field of education, visuality has come into prominence. Visuality is expressed in the science world by definition of visual literacy and defined as visual mathematics literacy in the science of mathematics (Bekdemir \& Duran, 2012).

Literacies like visual mathematics literacy or artistic mathematics that are born from the integration of common aspects about different literacies in the science world must be defined (Bekdemir \& Duran, 2012). However, other literacies like visual literacy and mathematics literacy should not be forgotten that they are supportive of general literacy (Tuman, 1994). Due to being in need of these literacies, the concept of "literacy" has been one of the main purposes of the education system of many countries (Bekdemir \& Duran, 2012).

Mathematical literacy is defined as "use of mathematics by the individual to notice and understand the role of mathematics in the world, to reach judgment grounded in sound basis and as to fulfill the needs of him/herself as a positive, concerned, and sensitive citizen" (Ministry of Education, 2011). In accordance with this definition, it can be said that mathematical literacy is not only knowing mathematical concepts and solving routine problems, but also identification with mathematics (Çolak, 2006). It was aimed that students should be trained as mathematics literate by standards asserted by National Council Teachers of Mathematics (NCTM) of America and main objectives of mathematics education in the 2005 Primary Education Mathematics Education Program (NCTM, 2000).

In parallel to this situation, it was pointed out by Harms (2000) that individuals with mathematical literacy competence can keep the mathematical concepts in mind, reflect the mathematical skills to daily life and use the mathematical information in analysis and synthesis situations. From this viewpoint, for individuals to have mathematical literacy competence, some basic competency and skills about mathematics should be gained (Bekdemir \& Duran, 2012). Since visual literacy concept is either supportive or a part of nearly all other literacies in the literature, it is in close relationship with other literacies (Kellner, 1998).

This conceptual relationship is stronger with mathematical literacy by providing better understanding to an individual by making abstract thoughts live, credible, and familiar and bringing the skill of processing same thoughts in different ways (İpek, 2003). This strong relationship between concepts formed a new literacy concept called "visual mathematics literacy" (Duran \& Bekdemir, 2013).

Many studies were conducted in related international fields about visual mathematics literacy. However, it is a newly studied field in Turkey due to reasons, such as new education programs, transition to constructivist education from traditional education. Bekdemir and Duran (2012) have developed a visual mathematics literacy scale (VMLS) for primary education two stage students and examined the relationship between mathematics 
literacy and visual mathematic success. Also, Duran (2013) has researched the opinions of seven grade students in primary education about mathematics literacy. It is thought that visual mathematics literacy of teachers and teacher candidates are as important as students in mathematics education. Since no other studies about visual mathematics literacy were encountered in literature searches made, development of VMLS to determine the visual mathematics literacy levels of primary education mathematics teacher candidates was considered important.

\section{Method}

This study features descriptive qualities. In the study, VMLS is developed for the purpose of determining visual mathematics literacies of students. At this point, draft scale is applied to a total of 325 students (176 females and 149 males) who study in Primary Education Mathematics Program of Faculty of Education, Cumhuriyet University and Faculty of Education, Dicle University Ziya Gökalp and final scale form was obtained.

\section{Sample/Study Group}

The sample group of the research is constituted of 325 students at levels of one, two, three, and four grades, studying in Primary Education Mathematics Program of Faculty of Education, Cumhuriyet University and Faculty of Education, Dicle University Ziya Gökalp.

\section{Stages of Study}

To develop the VMLS:

1. Composing of items and taking expert opinion;

2. Writing of draft scale form;

3. Application of the scale;

4. Analysis of data.

Stages were followed respectively (Büyüköztürk et al., 2009).

\section{Composing of Items}

In this part of the study, items that are oriented for gathering of data needed by looking at variables present in sub problems were composed. To compose an item pool, an essay composed of open-ended questions about the subject was given to a small focus group. Suitable question expressions were composed by conducting a content analysis on the essays.

\section{Writing of Items}

Items of the scale was prepared together with the items obtained from essays composed by teacher candidate researchers and literacy, mathematics literacy, visual literacy, and visual mathematics literacy concepts and visual mathematics literacy goals specified by International Student Evaluation Program, taking gains of geometry field specified by Ministry of Education into consideration. Then, the obtained items are edited in accordance with necessary expert opinions and the draft scale is given its final form.

\section{Taking of Expert Opinion and Composing of Pre-Application Form}

Firstly, composing the items within the scope of field needs is aimed. Then, expert opinions were consulted to ensure content and structure validity of the scale. Experts evaluated the items in the draft scale form in terms of content and structure validity. 


\section{Writing of Draft Scale Form}

VMLS, which is developed by the researcher, is a scale classified in pentad Likert type in terms of enabling direct determination of perceptions about visual mathematics literacy of primary education mathematics teachers. Each item in the scale is rated as "Never," "Seldom," "Sometimes," "Often," and "Always." All of the 54 items in the scale consists of positive items. The lowest score that can be obtained from the draft scale is 54 and the highest score is 270 . In the first part of the scale form, a short purpose of the study, instruction to how the coding shall be done and answer options are clearly expressed.

\section{Application of the Scale}

Scale development conditions are taken into consideration in the application. Actual application of the draft scale form with 54 items is conducted on 325 teacher candidates.

\section{Data Analysis}

In this part of the research, data analysis obtained from validity and reliability studies conducted for development of VMLS are described. An exploratory factor analysis is conducted to determine the structure validity of the visual mathematics literacy scale. By exploratory factor analysis, which factors related to visual mathematics literacy are measured was tried to be found. To determine whether the data structure is suitable for factor analysis, Kaiser Meyer Olkin (KMO) test and Barlett test was used. Also, to name the factors obtained, varimax rotation technique was used. Data obtained as a result of applications were analyzed by the using Statistical Package for the Social Sciences (SPSS) program. Relationships between the whole scale and sub-aspects are researched by Pearson Moment Multiplication Correlation. In the second stage, item analysis of VMLS is conducted. A 0.01 significance level was based on in the item analysis. Item total, item remaining, and item distinctiveness indexes are calculated, suitable items for the scale are determined. In the last part, while reliability studies are conducted, reliability coefficients of the whole scale and sub-aspects are measured respectively. Reliability of the scale is researched by calculating alpha coefficients and two half test reliability coefficients.

\section{Findings}

\section{Reliability Studies of VMLS and Sub Aspects}

In this section, determining the reliability degree of VMLS is aimed. To test the reliability, alpha coefficient and two half test correlations is calculated. The alpha coefficient calculated in the reliability study examines whether all the items in the scale express a whole that shows homogeneous structure (Kalayc1, 2010, p. 405). From this viewpoint, whether the scale expresses the whole is tested by produced statistics. Also, while calculating two half test reliability on the scale, two impartial equal halves are created and correlation coefficient is calculated. Two half test reliability is calculated by correlation coefficient that are calculated by using Spearman Brown formula from the viewpoint of relation between two halves of the test by dividing two equal halves as single-double, first half-last half, or impartial (Büyüköztürk, 2014, p. 170). Calculations are given in Table 1.

When the data in Table 1 examined, alpha coefficient of VMLS is calculated as 0.904 and two half test coefficient is 0.787 . When we examine the sub-aspects of the scale, highest data are in visual perception sub-aspect with measurements of 0.841 and 0.812 . Also, the lowest data are in pattern aspect with values of 0.664 and 0.516 . These obtained values are proving that the scale is a reliable measuring tool. 
Table 1

Reliability Coefficients of VMLS and Sub-Aspects

\begin{tabular}{lll}
\hline Alpha & Two half test & \\
\hline VMLS & 0.904 & 0.787 \\
VMLS-"Visual perception" & 0.841 & 0.812 \\
VMLS-"Geometric area" & 0.815 & 0.768 \\
VMLS-"Spatial intelligence" & 0.747 & 0.723 \\
VMLS-"Concreting" & 0.618 & 0.592 \\
VMLS-"Pattern" & 0.664 & 0.516 \\
\hline
\end{tabular}

\section{Validity Studies of VMLS}

A factor analysis is conducted to research structure validity of VMLS. Exploratory factor analysis is used as the factor analysis. By exploratory factor analysis, which mathematics literacy related factors were measured by scale items was tried to be determined. To ensure content validity, an item pool of 60 items is created that aims to measure visual mathematics literacy skills of teacher candidates in specific aspects. In accordance with necessary expert opinions and instructions, VMLS draft form with 54 items is composed. At the same time, opinions of five academic member's expert in the field of mathematics education and three primary education mathematics teachers are taken. One Turkish teacher and one literature teacher who are experts in terms of Turkish spelling rules and meaning structure are asked about their opinions. Scale is a pentad Likert type scale. Items are rated with expressions of " 5 = Always," " 4 = Often," " 3 = Sometimes," " 2 = Seldom," and " $1=$ Never."

\section{Factor Analysis of VMLS}

Suitability of the data for factor analysis can be examined with KMO coefficient and Barlett globality test. KMO coefficient informs about the suitability of data matrix for factor analysis and data structure for factor extraction. For factorability, KMO is expected to be higher than 0.60 . Barlett test examines whether there is a relationship between variables on the basis of partial correlations. Calculated chi-square statistic to be significant shows that data matrix is suitable. Also, test results being significant can be seen as a proof of normality of the scores (Büyüköztürk, 2014, p. 126).

Table 2

KMO and Bartlett Test Statistics of VMLS

\begin{tabular}{llll}
\hline KMO test & Barlett test & & \\
\hline \multirow{2}{*}{0.878} & $X^{2}$ & $s d$ & $p$ \\
\cline { 2 - 4 } & 3748.450 & 666 & 0.000 \\
\hline
\end{tabular}

When the Table 2 is examined, it is seen that KMO value is 0.878 and Barlett test value is 3748.450 ( $p<$ $0.05)$. These values are equivalent of suitability of data in conducting of factor analysis. In light of these data, 17 of the 54 items which had exploratory factor analysis applied are removed from the scale. It may be found adequate that the variance explained in single factor scales to be $30 \%$ or more. In multi factor scales, it is expected that the explained variance to be higher. Since the explained variance being high is interpreted as a sign of measuring of related concept or structure to a good degree, to increase the explained variance, the number of important factors can be increased or higher factor load values can be searched in selection of explained items (Büyüköztürk, 2014, p. 125). The eigenvalues and variance rates of factors are given in Table 3. 
Table 3

Eigenvalues, Variance, and Cumulative Variance Rates of Factors of VMLS Explains

\begin{tabular}{llll}
\hline Factors & Eigenvalue & Variance $(\%)$ & Cumulative variance $(\%)$ \\
\hline Factor 1 & 8.369 & 12.417 & 12.417 \\
Factor 2 & 3.026 & 10.939 & 23.356 \\
Factor 3 & 1.974 & 8.263 & 31.620 \\
Factor 4 & 1.629 & 6.390 & 38.009 \\
Factor 5 & 1.374 & 6.237 & 44.246 \\
\hline
\end{tabular}

As seen in Table 3, all the eigenvalues are higher than one and variance rates explained by factors are considerably good. Total variance rate explained by factors is seen as $44.246 \%$. Explained total variance being high means this variance rate explains the scale structure in good level. In factor analysis, maximization of common factor variance or common variance caused by factors on each variable is aimed. This value depends on load values of each factor and is equal to squares of load values in important factors of an item (Büyüköztürk, 2014, p. 124). In the study, factors with eigenvalue higher than one are considered as important factors. As a result, a five factors scale is composed. Again, when we examine the line graph of factor eigenvalue, five important values is seen. The factor with high momentum fast drops gives the number of important factors (Büyüköztürk, 2014, p. 125). The factor eigenvalue line graph obtained as a result of study analysis is as follows (see Figure 1).

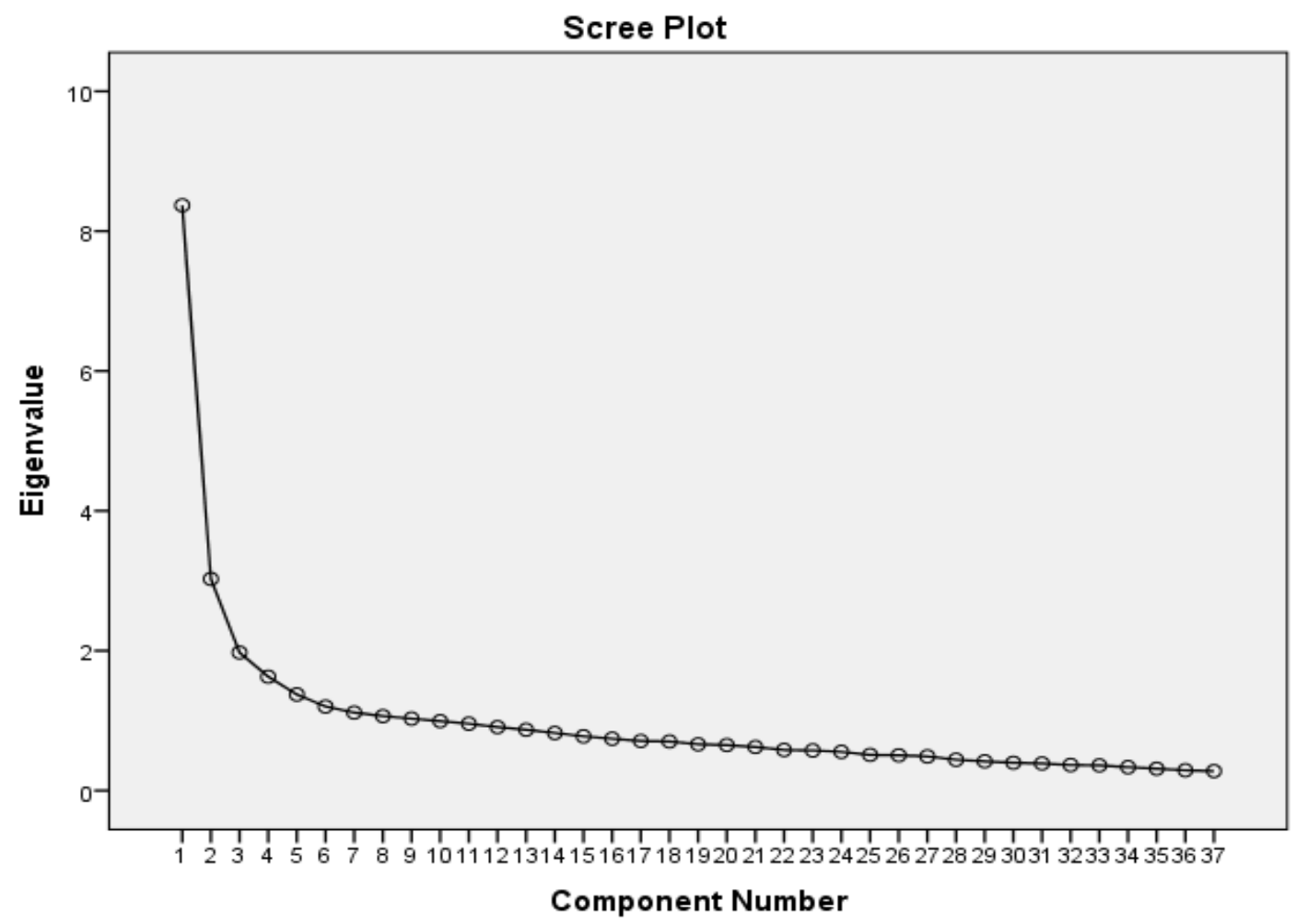

Figure 1. Factor eigenvalue line graph of VMLS.

Researcher obtained the data in this study by using vertical rotation method. The values of item loads obtained as a result of produced statistics under each factor are given in Table 4. 
Table 4

Factor Loads of Sub-Factors and Items According to Exploratory Factor Analysis

\begin{tabular}{|c|c|c|c|c|c|}
\hline Item & Factor 1 & Factor 2 & Factor 3 & Factor 4 & Factor 5 \\
\hline 48 & 0.646 & & & & \\
\hline 49 & 0.633 & & & & \\
\hline 45 & 0.621 & & & & \\
\hline 34 & 0.598 & & & & \\
\hline 33 & 0.563 & & & & \\
\hline 44 & 0.540 & & & & \\
\hline 47 & 0.531 & & & & \\
\hline 29 & 0.504 & & & & \\
\hline 41 & 0.483 & & & & \\
\hline 39 & 0.475 & & & & \\
\hline 38 & 0.466 & & & & \\
\hline 54 & 0.462 & & & & \\
\hline 43 & 0.454 & & & & \\
\hline 31 & 0.410 & & & & \\
\hline 13 & & 0.716 & & & \\
\hline 42 & & 0.654 & & & \\
\hline 46 & & 0.618 & & & \\
\hline 16 & & 0.567 & & & \\
\hline 40 & & 0.557 & & & \\
\hline 26 & & 0.539 & & & \\
\hline 12 & & 0.538 & & & \\
\hline 27 & & 0.446 & & & \\
\hline 17 & & 0.438 & & & \\
\hline 53 & & 0.432 & & & \\
\hline 1 & & & & 0.715 & \\
\hline 24 & & & & 0.688 & \\
\hline 7 & & & & 0.685 & \\
\hline 37 & & & & 0.601 & \\
\hline 9 & & & & 0.512 & \\
\hline 4 & & & 0.665 & & \\
\hline 10 & & & 0.555 & & \\
\hline 3 & & & 0.542 & & \\
\hline 8 & & & 0.458 & & \\
\hline 6 & & & 0.428 & & \\
\hline 23 & & & & & 0.657 \\
\hline 21 & & & & & 0.637 \\
\hline 28 & & & & & 0.590 \\
\hline
\end{tabular}

According to data in Table 4, it is determined that item factor loads of the scale change between 0.410 and 0.716. Again, from the viewpoint of Table 4, it can be said that first factor has 14, second factor has 10, third factor has five, fourth factor has five, and fifth factor has three items. As a result, 17 items are removed from the scale of 54 items and a scale of 37 items with five sub factors is obtained. Factors are named considering the items found in each of them.

\section{Relationship of VMLS With Its Sub-Aspects}

In this part of the research, the relationship between the VMLS that is factor analyzed and its sub-aspects 
is examined. In the calculated correlation values, it is significant in $p<0.01$ level. Correlation values related to whole scale and each sub-aspect is shown in Table 5.

When the Table 5 is examined, it is seen that VMLS has the most relation with its visual perception aspect which has the highest correlation value of 0.848 among its sub-aspects. The scale has the least relation with spatial intelligence aspect which has 0.664 correlation value. Again, when we look at the sub-aspects, the most relation is between concretion and pattern sub-aspects with 0.475 correlation values and the least relation is between pattern and spatial intelligence with 0.332 correlation values. Also, it is seen that there is a positive and significant correlation (relation) between all variables.

Table 5

Correlation Table Between VMLS and Sub-Aspects

\begin{tabular}{|c|c|c|c|c|c|c|}
\hline & VMLS & $\begin{array}{l}\text { Visual } \\
\text { perception }\end{array}$ & Geometric area & $\begin{array}{l}\text { Spatial } \\
\text { intelligence }\end{array}$ & Concretion & Pattern \\
\hline VMLS & 1.000 & 0.848 & 0.735 & 0.664 & 0.689 & 0.666 \\
\hline Visual perception & 0.848 & 1.000 & 0.400 & 0.419 & 0.452 & 0.452 \\
\hline Geometric area & 0.735 & 0.400 & 1.000 & 0.417 & 0.411 & 0.505 \\
\hline Spatial intelligence & 0.664 & 0.419 & 0.417 & 1.000 & 0.416 & 0.332 \\
\hline Concretion & 0.689 & 0.452 & 0.411 & 0.416 & 1.000 & 0.475 \\
\hline Pattern & 0.666 & 0.452 & 0.505 & 0.332 & 0.475 & 1.000 \\
\hline
\end{tabular}

\section{Item Analysis of VMLS}

In this section, item analysis of the VMLS is found. Firstly, the analysis concerning the whole of the scale is given and then these analyses were checked individually for each item.

Table 6

Item Analysis Data Related to the Whole of VMLS

\begin{tabular}{lc}
\hline Number of items & 37 \\
\hline Average & 133.9077 \\
Median & 134.0000 \\
Mod & 134.0000 \\
Standard deviation & 18.3012 \\
Variance & 334.9360 \\
Amplitude & 102.0000 \\
Minimum & 76.0000 \\
Maximum & 178.0000 \\
Skewness & -0.2510 \\
Skewness standard error & 0.1350 \\
$p$ value for skewness & $>0.01$ \\
Kurtosis & -0.7600 \\
Kurtosis standard error & 0.2700 \\
$p$ value for kurtosis & $>0.05$ \\
\hline
\end{tabular}

When the data of Table 6 are examined, it is seen that average is 133.9077, standard deviation is 18.3012, and variance is 334.9360. Also, it is found that skewness coefficient is -0.2510 and kurtosis coefficient is -0.7600 . When we check the skewness $(p>0.01)$ and kurtosis $(p>0.05)$ coefficients of VMLS, data are seen to be suitable for normal distribution. Arithmetic average and standard deviation values related to all items of the scale are given in Table 7. 
Table 7

Arithmetic Average, Standard Deviation, and Variance Values of All Items of VMLS

\begin{tabular}{|c|c|c|c|c|}
\hline Item & Number of students & Arithmetic average & Standard deviation & Variance \\
\hline 1 & 325 & 3.50 & 1.053 & 1.109 \\
\hline 3 & 325 & 4.12 & 0.858 & 0.736 \\
\hline 4 & 325 & 3.09 & 1.204 & 1.449 \\
\hline 6 & 325 & 3.13 & 1.399 & 1.956 \\
\hline 7 & 325 & 3.26 & 1.139 & 1.297 \\
\hline 8 & 325 & 4.22 & 0.928 & 0.861 \\
\hline 9 & 325 & 3.67 & 1.097 & 1.204 \\
\hline 10 & 325 & 3.42 & 1.162 & 1.350 \\
\hline 12 & 325 & 4.23 & 0.910 & 0.828 \\
\hline 13 & 325 & 4.51 & 0.796 & 0.633 \\
\hline 16 & 325 & 4.27 & 0.872 & 0.760 \\
\hline 17 & 325 & 4.02 & 0.961 & 0.923 \\
\hline 21 & 325 & 4.04 & 0.987 & 0.974 \\
\hline 23 & 325 & 3.80 & 1.007 & 1.014 \\
\hline 24 & 325 & 3.59 & 1.043 & 1.088 \\
\hline 26 & 325 & 4.24 & 0.938 & 0.880 \\
\hline 27 & 325 & 3.94 & 0.866 & 0.750 \\
\hline 28 & 325 & 3.90 & 1.012 & 1.025 \\
\hline 29 & 325 & 3.52 & 1.177 & 1.386 \\
\hline 31 & 325 & 3.36 & 1.025 & 1.051 \\
\hline 33 & 325 & 2.68 & 1.131 & 1.280 \\
\hline 34 & 325 & 3.13 & 1.022 & 1.045 \\
\hline 37 & 325 & 3.44 & 1.025 & 1.050 \\
\hline 38 & 325 & 3.68 & 1.064 & 1.132 \\
\hline 39 & 325 & 3.37 & 1.059 & 1.123 \\
\hline 40 & 325 & 4.04 & 1.085 & 1.178 \\
\hline 41 & 325 & 3.42 & 1.035 & 1.071 \\
\hline 42 & 325 & 4.36 & 0.873 & 0.762 \\
\hline 43 & 325 & 3.36 & 1.180 & 1,392 \\
\hline 44 & 325 & 3.37 & 1.135 & 1,288 \\
\hline 45 & 325 & 2.59 & 1.223 & 1.496 \\
\hline 46 & 325 & 4.38 & 0.917 & 0.841 \\
\hline 47 & 325 & 3.44 & 1.138 & 1.296 \\
\hline 48 & 325 & 3.02 & 1.118 & 1.250 \\
\hline 49 & 325 & 2.74 & 1.155 & 1.334 \\
\hline 53 & 325 & 4.15 & 0.950 & 0.902 \\
\hline 54 & 325 & 2.93 & 1.318 & 1.736 \\
\hline Average & 325 & 3.52 & 1.023 & 1.120 \\
\hline
\end{tabular}

When the data of Table 7 are examined, the highest average belongs to item 46 with 4.38 . The lowest average belongs to item 45 with 2.59. Also, calculation of average of arithmetic average is 3.52, standard deviation is 1.023 , and variance is 1.120 . Item total, item remaining, and item distinctiveness values are given in Table 8 . 
Table 8

Item Analysis Values of VMLS

\begin{tabular}{|c|c|c|c|c|c|c|c|}
\hline Item & $\begin{array}{l}\text { Number of } \\
\text { students }\end{array}$ & Item total & Item distinctiveness & Average & $\begin{array}{l}\text { Standard } \\
\text { deviation }\end{array}$ & $t$ & $p$ \\
\hline \multirow{2}{*}{1} & \multirow{2}{*}{325} & \multirow{2}{*}{0.314} & UPPER \%27 & 4.02 & 0.819 & \multirow{2}{*}{-6.446} & \multirow{2}{*}{0.000} \\
\hline & & & LOWER \%27 & 3.14 & 1.000 & & \\
\hline \multirow{2}{*}{3} & \multirow{2}{*}{325} & \multirow{2}{*}{0.385} & UPPER \%27 & 4.52 & 0.676 & \multirow{2}{*}{-7.505} & \multirow{2}{*}{0.000} \\
\hline & & & LOWER \%27 & 3.64 & 0.873 & & \\
\hline \multirow{2}{*}{4} & \multirow{2}{*}{325} & \multirow{2}{*}{0.329} & UPPER \%27 & 3.70 & 1.181 & \multirow{2}{*}{-7.426} & \multirow{2}{*}{0.000} \\
\hline & & & LOWER \%27 & 2.47 & 1.017 & & \\
\hline \multirow{2}{*}{6} & \multirow{2}{*}{325} & 0394 & UPPER \%27 & 4.01 & 1.163 & & \\
\hline & & 0.394 & LOWER \%27 & 2.30 & 1.146 & -9.885 & 0.000 \\
\hline & & & UPPER \%27 & 3.97 & 1.005 & & \\
\hline 1 & 325 & 0.479 & LOWER \%27 & 2.47 & 0.909 & -10.412 & 0.000 \\
\hline 8 & & 0286 & UPPER \%27 & 4.65 & 0.676 & & O $0 \Omega$ \\
\hline 8 & 325 & 0.386 & LOWER \%27 & 3.67 & 1.047 & -1.414 & 0.000 \\
\hline 0 & 325 & 0420 & UPPER \%27 & 4.12 & 0.877 & -7803 & 00 \\
\hline 9 & 325 & 0.420 & LOWER \%27 & 2.92 & 1.157 & -7.803 & 0.000 \\
\hline 10 & 325 & 0446 & UPPER \%27 & 4.08 & 1.003 & & 0000 \\
\hline 10 & 325 & 0.440 & LOWER \%27 & 2.58 & 1.090 & -9.523 & 0.000 \\
\hline 12 & 325 & 0446 & UPPER \%27 & 4.72 & 0.543 & -9243 & 0000 \\
\hline 12 & 325 & 0.440 & LOWER \%27 & 3.60 & 1.000 & -9.243 & 0.000 \\
\hline 13 & 325 & 0327 & UPPER \%27 & 4.81 & 0.474 & & \\
\hline 13 & 325 & 0.322 & LOWER \%27 & 4.14 & 0.949 & -5.975 & 0.000 \\
\hline & 325 & 0455 & UPPER \%27 & 4.76 & 0.501 & & 000 \\
\hline 16 & 325 & 0.455 & LOWER \%27 & 3.77 & 0.979 & -8.493 & 0.000 \\
\hline & & & UPPER \%27 & 4.46 & 0.708 & & \\
\hline 17 & 325 & 0.373 & LOWER \%27 & 3.53 & 0.994 & -7.151 & 0.000 \\
\hline 21 & 325 & 0455 & UPPER \%27 & 4.62 & 0.594 & & \\
\hline 21 & 325 & 0.455 & LOWER \%27 & 3.39 & 0.964 & -10.247 & 0.000 \\
\hline 23 & 325 & 0525 & UPPER \%27 & 4.46 & 0.641 & & \\
\hline 23 & 325 & 0.525 & LOWER \%27 & 3.05 & 0.982 & -11.372 & 0.000 \\
\hline & & & UPPER \%27 & 4.13 & 0.786 & & \\
\hline 24 & 325 & $0.4 / 8$ & LOWER \%27 & 2.94 & 1.010 & -8.766 & 0.000 \\
\hline 26 & 325 & 0364 & UPPER \%27 & 4.70 & 0.803 & -6631 & 0000 \\
\hline & 325 & 0.304 & LOWER \%27 & 3.82 & 0.953 & & \\
\hline 27 & 325 & 0455 & UPPER \%27 & 4.48 & 0.642 & -9 987 & 0000 \\
\hline 21 & 325 & 0.455 & LOWER \%27 & 3.43 & 0.755 & -9.981 & 0.000 \\
\hline 28 & 325 & 0440 & UPPER \%27 & 4.46 & 0.724 & -8663 & 0000 \\
\hline 28 & 325 & 0.440 & LOWER \%27 & 3.33 & 1.003 & -8.003 & 0.000 \\
\hline 20 & 325 & 0482 & UPPER \%27 & 4.27 & 0.997 & & \\
\hline 29 & 325 & 0.482 & LOWER \%27 & 2.80 & 1.105 & -9.317 & 0.000 \\
\hline 31 & 325 & 0386 & UPPER \%27 & 3.92 & 0.932 & -7899 & 0000 \\
\hline 31 & 325 & 0.386 & LOWER \%27 & 2.81 & 0.945 & -1.899 & 0.000 \\
\hline & & & UPPER \%27 & 3.29 & 0.920 & & \\
\hline 33 & 325 & 0.388 & LOWER \%27 & 2.09 & 1.023 & -8.262 & 0.000 \\
\hline 34 & 325 & 0500 & UPPER \%27 & 3.83 & 0.801 & -10689 & 0000 \\
\hline 34 & 325 & 0.500 & LOWER \%27 & 2.47 & 0.896 & -10.689 & 0.000 \\
\hline 37 & 325 & 0410 & UPPER \%27 & 4.06 & 0.803 & & $0 \Omega 0$ \\
\hline 31 & 325 & 0.410 & LOWER \%27 & 2.95 & 1.005 & -8.063 & 0.000 \\
\hline 38 & 325 & 0518 & UPPER \%27 & 4.36 & 0.678 & 10 280 & 0000 \\
\hline 38 & 325 & 0.518 & LOWER \%27 & 2.99 & 1.056 & -10.289 & 0.000 \\
\hline 30 & 325 & 0547 & UPPER \%27 & 4.15 & 0.820 & & \\
\hline 39 & 325 & 0.542 & LOWER \%27 & 2.72 & 0.952 & -10.913 & 0.000 \\
\hline 40 & 325 & 0453 & UPPER \%27 & 4.73 & 0.517 & & \\
\hline 40 & 325 & 0.453 & LOWER \%27 & 3.38 & 1.107 & -10.454 & 0.000 \\
\hline 41 & 325 & 0460 & UPPER \%27 & 4.02 & 0.929 & -8775 & 0000 \\
\hline 41 & 325 & 0.400 & LOWER \%27 & 2.76 & 0.983 & $-8.7 / 5$ & 0.000 \\
\hline 47 & 325 & 0416 & UPPER \%27 & 4.79 & 0.488 & & $0 \Omega 0 \Omega$ \\
\hline 42 & 325 & 0.410 & LOWER \%27 & 3.81 & 1.081 & -1.184 & 0.000 \\
\hline
\end{tabular}


(Table 8 to be continued)

\begin{tabular}{|c|c|c|c|c|c|c|c|}
\hline 43 & 325 & 0.393 & $\begin{array}{l}\text { UPPER \%27 } \\
\text { LOWER \%27 }\end{array}$ & $\begin{array}{l}3.93 \\
2.61\end{array}$ & $\begin{array}{l}0.939 \\
1.159\end{array}$ & -8.323 & 0.000 \\
\hline 44 & 325 & 0.436 & $\begin{array}{l}\text { UPPER \%27 } \\
\text { LOWER \%27 }\end{array}$ & $\begin{array}{l}4.03 \\
2.68\end{array}$ & $\begin{array}{l}0.923 \\
1.034\end{array}$ & -9.178 & 0.000 \\
\hline 45 & 325 & 0.345 & $\begin{array}{l}\text { UPPER \%27 } \\
\text { LOWER \%27 }\end{array}$ & $\begin{array}{l}3.18 \\
2.01\end{array}$ & $\begin{array}{l}1.163 \\
1.140\end{array}$ & -6.749 & 0.000 \\
\hline 46 & 325 & 0.340 & $\begin{array}{l}\text { UPPER \%27 } \\
\text { LOWER \%27 }\end{array}$ & $\begin{array}{l}4.79 \\
3.92\end{array}$ & $\begin{array}{l}0.593 \\
1.085\end{array}$ & -6.599 & 0.000 \\
\hline 47 & 325 & 0.535 & $\begin{array}{l}\text { UPPER \%27 } \\
\text { LOWER \%27 }\end{array}$ & $\begin{array}{l}4.07 \\
2.57\end{array}$ & $\begin{array}{l}0.939 \\
1.026\end{array}$ & -10.143 & 0.000 \\
\hline 48 & 325 & 0.475 & $\begin{array}{l}\text { UPPER \%27 } \\
\text { LOWER \%27 }\end{array}$ & $\begin{array}{l}3.70 \\
2.27\end{array}$ & $\begin{array}{l}1.049 \\
0.979\end{array}$ & -9.332 & 0.000 \\
\hline 49 & 325 & 0.310 & $\begin{array}{l}\text { UPPER \%27 } \\
\text { LOWER \%27 }\end{array}$ & $\begin{array}{l}3.30 \\
2.25\end{array}$ & $\begin{array}{l}1.122 \\
1.096\end{array}$ & -6.317 & 0.000 \\
\hline 53 & 325 & 0.465 & $\begin{array}{l}\text { UPPER \%27 } \\
\text { LOWER \%27 }\end{array}$ & $\begin{array}{l}4.69 \\
3.52\end{array}$ & $\begin{array}{l}0.513 \\
1.114\end{array}$ & -8.934 & 0.000 \\
\hline 54 & 325 & 0.371 & $\begin{array}{l}\text { UPPER \%27 } \\
\text { LOWER \%27 }\end{array}$ & $\begin{array}{l}3.69 \\
2.20\end{array}$ & $\begin{array}{l}1.221 \\
1.136\end{array}$ & -8.351 & 0.000 \\
\hline
\end{tabular}

When Table 8 is examined, item distinctiveness indexes are determined to be significant $(p<0.01)$. Also, item total correlations are calculated as lowest value of 0.310 and highest value of 0.542 .

\section{Discussion, Conclusion, and Suggestions}

To ensure the content validity of VMLS, opinions of academicians and teachers working within the body of Ministry of Education about whether the items constituting the scale are related to visual mathematics literacy and suitable to primary education mathematics curriculum and to the level of students. Factor analysis is used for structure validity. According to this, the items in the scale are gathered in five factors which are "visual perception," "geometric area," "spatial intelligence," "concretion," and "pattern." These factors explain $44.246 \%$ of the total variance. To provide face validity, the opinions desired to be measured are expressed clearly in the items and written suitably to the subject. It is seen that the scale named as VMLS is a reliable measuring tool in terms of internal consistency coefficient $(\alpha=0.904)$ and item-total correlations. When the relation of the scale with its lower aspects is examined, it is seen that visual mathematics literacy scale is related most with lower aspect of visual perception with the value of 0.848 correlations and least with lower aspect of spatial intelligence with the value of 0.664 correlations. When we look at the lower aspects between each other, the highest relation is between concretion and pattern lower aspects with a correlation value of 0.474 and lowest relation is between pattern and spatial intelligence lower aspects with a correlation value of 0.332. Also, a positive and significant correlation (relation) is seen between all variables. The opinion of Bandura (2007) about the perception of self-efficacy affects the performances of students is seen scientifically important (as cited in Altıntaş, Özdemir, \& Kerpiç, 2012). Van Garderen and Montaque (2003) and Hegarty and Kozhevnikov (1999) said that visual elements used in problem solving process would increase the mathematical success (Kuzle, 2011). Bekdemir and Duran (2012) had developed a VMLS oriented for primary education students, variance rate of the scale was found $41.81 \%$ and Cronbach alpha internal consistency coefficient was found 0.943 . In the education process, teachers take the responsibility of training an individual to create a community with high human quality. In this context, the individual shall be able to improve the learning skills, update the professional knowledge, learn visual language and visual literacy, and transfer the information suitable to its purpose, read and think multi-directional and have intellectual responsibility 
(Gemalmayan, 2014). As a result, it can be said that the VMLS developed by the researcher is a scale that can determine the visual mathematical literacy perceptions of primary education mathematics teacher candidates, valid, reliable, and useful. Also, the scale can be used in determination of the visual mathematical literacy levels of teachers and teacher candidates in other branches, checking the relation of visual mathematics literacy with other variables or in researches covering different groups.

\section{References}

Altıntaş, E., Özdemir, A. Ş., \& Kerpiç, A. (2012). Comparison of perception of pre-service teachers' self-efficacy of mathematical literacy according to their programs. Trakya University, Journal of Faculty of Education, 2(2), 26-34.

Bekdemir, M., \& Duran, M. (2012). Development of a visual math literacy self-efficacy perception scale (VMLSEPS) for elementary students. Ondokuz Mayls University, Journal of Faculty of Education, 31(1), 89-115.

Büyüköztürk, Ş. (2014). Data analysis handbook for social sciences (18th ed.). Ankara: Pegem AkademiYayıncıl1k.

Büyüköztürk, Ş., KılıçÇakmak, E., Akgün, Ö. E., Karadeniz, Ş., \& Demirel, F. (2009). Scientific research methods (Extended 3rd ed.). Ankara: Pegem Academy Publishing.

Çolak, S. (2006). An experimental study on the impact of material use on mathematical literary in the context of geometrical concepts in sixth grade students (Unpublished master's thesis, Gazi University, Ankara).

Debes, J. (1968). Some foundations of visual literacy. Audio Visual Instruction, 13, 961-964.

Duran, M. (2012). Relationship between visual mathematics literacy self-efficacy perceptions and visual mathematical success of primary education seventh grade students (Unpublished master's thesis, Erzincan University, Erzincan).

Duran, M. (2013). Opinions of primary seventh grade students about visual mathematics literacy. Mehmet Akif Ersoy University, Journal of Graduate School of Educational Sciences, 2, 38-51.

Duran, M., \& Bekdemir, M. (2013). Evaluation of visual mathematics literacy self-efficacy perception and visual mathematics success. Pegem Education and Training Magazine, 3(3), 27-40.

Ersoy, Y. (2003). Mathematics literacy-II: Objectives, competencies and skills to be developed. Association of Mathematicians. Retrieved March 31, 2010, from http://matder.org.tr

Gemalyaman, R. Y. (2014). Visual literacy and basic design teaching in the visual arts education. Sakarya University, Journal of Faculty of Education, 95-120.

Harms, T. J. (2000). Analysis of Minnesota students' mathematical literacy on TIMSS, NAEP, and MNBST (Doctoral dissertation, University of North Dakota, North Dakota, ABD).

Hegarty, M., \& Kozhevnikov, M. (1999). Types of visual-spatial representations and mathematical problem solving. Journal of Educational Psychology, 91(4), 684.

İpek, İ. (2003). Computers, visual design and visual learning strategies. The Turkish Online Journal of Educational Technology (T.O.J.E.T.), 2(3), 68-76.

Kalayc1, N. (2010). Problem solving in social sciences and its practices. Ankara: Gazi Bookstore.

Kellner, D. (1998). Multiple literacies and critical pedagogy in a multicultural society. Educational Theory, 48(1), $103-122$.

Kuzle, A. (2011). Problem solving and metacognitive behavior models in dynamic geometry environment. International Electronic Journal of Mathematics Education, 8, 20-40.

Karunaratne, W. (2000, September 21-23). Case for adult literacy in South East Asia with special reference to Sri Lanka. In Australian Council for Adult Literacy Conference, Perth, Australia.

Ministry of National Education (MEB). (2005). Mathematics Curriculum and Guide (9th and 12th grades). Ankara: Publishing House of Ministry of Education.

MEB. (2011). PISA Bulletin II. Retrieved June 16, 2012, from http://earged.meb.gov.tr

National Council of Teachers of Mathematics (NCTM). (2000). Principal and standards for school mathematics. Reston: NCTM Publications.

Sanalan, V. A., Sülün, A., \& Çoban, T. A. (2007). Visual literacy. Journal of Erzincan Faculty of Education, 9(2), 33-47.

Tuman, J. P. (1994). The politics of labor quiescence and confrontation in the Mexican Automobile Industry, 1980-1992. Los Angeles: University of California.

Van Garderen, D., \& Montague, M. (2003). Visual-Spatial representation, mathematical problem solving, and students of varying abilities. Learning Disabilities Research \& Practice, 18(4), 246-254. 